\title{
Leadership Innovation and Implement Organizational Change and Lead a New Initiative through Adoption of the Innovation and Change Management Practices for Shiraz Industries Private Limited Company: A Survey from Pakistan
}

\section{Mustafa M*}

Doctorate in Business Administration, University of Wales Trinity Saint David, United Kingdom

\begin{abstract}
Top management plays a pivotal role in adding value to the company by using smartly designed strategies, which can help strengthening the company's position. In this report main emphasis is placed on leadership, innovation and change practices in Shiraz Industries private limited. This report identifies the problematic areas and suggests workable and doable solutions to solve the problems. To analyze and understand the company's current position SWOT analysis is undertaken to identify the strengths and weaknesses internally of the company, and opportunities and threats externally of the company. Two models of innovation and change are used to propose and implement organizational change through adoption of the innovation and change management practices and lead a new initiative. The company top management has a bureaucratic style of doing the things in the company. The company has not proper structure and hierarchy especially no formal marketing department. By using the innovation Genome Framework, which gives the top management the clear understanding that they should give employees more freedom and the team, act should be more autonomous. And within the organization they should create sense of cohesion amongst the employees. Top management should look for measures of improvement not just the task accomplishment and goals. The Pentathlon Framework model of innovation is used to see the company innovation strategy and give the idea, prioritization and the implementation of complete process. The role of innovation, services and business process must be communicated to the workforce by the top management. Managers need to look at the things with and operate from a broader perspective especially when generating ideas, improving processes, products and services. Customers demand and need should be focused on and given priority. Goals can be achieved faster by effective cross-functional development testing and prototyping. Kotter's change model and its implication can cater for the company's sense of urgency, and, top management should take the pulse of their company employees. True leaders and key stakeholders in the company are to be identified for change. Create a powerful vision and to communicate amongst the masses, and people anxieties and concerns to be properly addressed. Top management should plan and create the short-term wins. McKinsey $7 \mathrm{~s}$ models of change for what should be the company strategy and how the structure and system should be for the proper check and balance and exact job description for the work place. The shared values, style, staff and skilled and focused to achieve the desired goals. If the company applies all the above models strategy and implement, it is hopes that the company will definitely improve its performance.
\end{abstract}

Keywords: Innovation; SWOT analysis; Kotter's change model

\section{Shiraz Industries Company Report}

\section{Background Shiraz industries report}

This company report has been analyzed as a strategic consultant for Shiraz Industries private limited. The major problem areas/ departments of the company, were focused i.e., Sales and Marketing department.

\section{Aim}

The aim is to propose and implement organizational change and leads a new initiative through adoption of the innovation and change management practices for Shiraz Industries private limited company and identified the leadership, innovation and change management problem and suggests solutions using innovation and change management models.

\section{Objectives}

- To analyze evaluate the leadership innovation and change management problems faced by the company.

- To propose organizational change through adoption of the innovation and change management practices.
- To suggest solution and implementation of innovation and change for Shiraz Industries private limited.

\section{Shiraz industries background}

Shiraz industries is a woven polypropylene bags manufacturing company and very well established in the field of manufacturing polypropylene products. 1.8 million Bags a month is the average production line of this company [1]. The company has installed the world best polypropylene machinery to get the supreme material to attract the customers and the market. The industries for which Shiraz

*Corresponding author: Mamoon Mustafa, Doctorate in Business Administration University of Wales Trinity Saint David, United Kingdom, Tel: 541-737-4411; E-mail: ursmamoon@hotmail.com

Received July 27, 2017; Accepted August 16, 2017; Published August 26, 2017

Citation: Mustafa M (2017) Leadership Innovation and Implement Organizationa Change and Lead a New Initiative through Adoption of the Innovation and Change Management Practices for Shiraz Industries Private Limited Company: A Survey from Pakistan. J Bus Fin Aff 6: 278. doi: 10.4172/2167-0234.1000278

Copyright: (c) 2017 Mustafa M. This is an open-access article distributed under the terms of the Creative Commons Attribution License, which permits unrestricted use, distribution, and reproduction in any medium, provided the original author and source are credited. 
Citation: Mustafa M (2017) Leadership Innovation and Implement Organizational Change and Lead a New Initiative through Adoption of the Innovation and Change Management Practices for Shiraz Industries Private Limited Company: A Survey from Pakistan. J Bus Fin Aff 6: 278. doi: $10.4172 / 2167-0234.1000278$

Page 2 of 9

Industries are producing bags are fertilizer, chemical, flour, agriculture, textile and sugar industries Shirazindustry.com, 2014.

\section{Shiraz industries problem statement using SWOT analysis}

An important part for the existing business position is to look for the planning process and decide which internal and external factors may affect the existing business. By performing the SWOT analysis to figure out the internal and external problem areas of the business and looking at the future and current situation (Figure 1 and Table 1).

\section{Innovation Models}

The strategy and introduction of innovation and change management will be done through following innovation models.

\section{Innovation genome model for Shiraz industries private limited}

The four hierarchy of Genome model using each quadrant to strategic priorities for Shiraz Industries private limited are as follows (Tables 2-5 and Figure 2).

\section{Pentathlon framework model for Shiraz industries private limited}

Design Thinking Methodology (Figure 3).

Innovation strategy: 1. Top management is responsible for achieving and development of innovation strategy by assessing the market trend. 2. For new innovation of product need expertise in the relevant technology. 3. Top management of the company must communicate role of innovation in services and business process innovation. 4. $\mathrm{R} \& \mathrm{D}$ and market development capabilities are required for first to market approach.

Ideas: 1 . The managers should support team and individual level creativity to create organizational environment. 2. Within and outside the organization knowledge should be harness by the creativity. 3. To streamline the process that serves the customers and large volume of creativity ideas need to be generated to address the product and service related requirement of the latent or existing customer. 4. For idea generation scope needs to be kept wide as innovation includes improved or new process, services and new product.
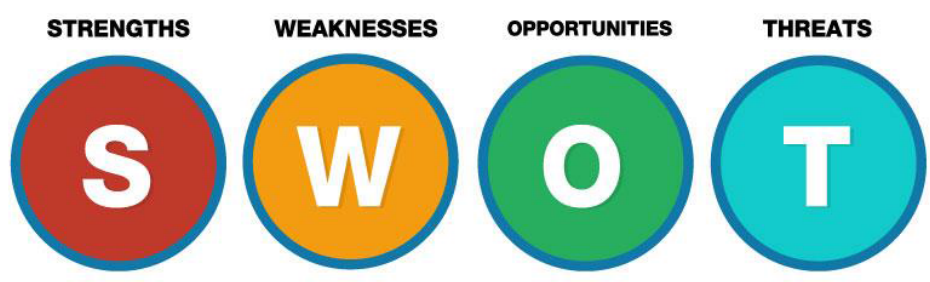

Figure 1: EZ Marketing

\begin{tabular}{|c|c|}
\hline Strengths & Weaknesses \\
\hline The company has a state of the art machinery & No proper hierarchy and structure of the company \\
\hline $\begin{array}{l}\text { Good infrastructure and location of the company from } \\
\text { business point. }\end{array}$ & Marketing department is not formal \\
\hline Very skilled operators, labor and technical team & No appropriate marketing strategy \\
\hline The company has good financial resources & Less staff in the marketing department \\
\hline Refine finishing and good quality product & Shallow skilled sales and marketing staff with no marketing expertise \\
\hline Well-managed order delivery time & $\begin{array}{l}\text { Very less budget for the marketing and the advertisement that fails to generate sales and brand } \\
\text { recognition in the niche market }\end{array}$ \\
\hline $\begin{array}{l}\text { In terms of polypropylene bags production it is a leading } \\
\text { company in the country }\end{array}$ & No market field survey research on the need of the customers and the data of the market is outdated \\
\hline \multicolumn{2}{|l|}{ Existing clients are the top industries in their field } \\
\hline Opportunities & Threats \\
\hline A new international market & In the local market new competitors. \\
\hline For rapid growth new market segment is poised & A new innovative products and services are introduced by the competitors. \\
\hline International marketing growing demand like India, UK & Superior channel of distribution by the competitors \\
\hline Loyal customers in the market & Customers taste and fashion changed \\
\hline \multirow[t]{2}{*}{ Great potential in new market } & In the market similar products with lots of competitors with low price. \\
\hline & Market becomes more cost sensitive. \\
\hline \multirow[t]{9}{*}{ Actions and Priorities } & Employees should be given freedom and team act should be more autonomous \\
\hline & $\begin{array}{l}\text { Atmosphere within the company should sense of family and work efficiency and loyalty will be shared as } \\
\text { a cause }\end{array}$ \\
\hline & Top management (CEO \& Directors) should be more supportive and facilitative \\
\hline & When doing change in implementation and planning involve the people who will be affected \\
\hline & $\begin{array}{c}\text { The objective, time frame and responsibilities should be clearly define and properly communicated and } \\
\text { then give freedom to experiment in the field. }\end{array}$ \\
\hline & In the organization create sense of cohesion \\
\hline & In change situation ask for lot of advice \\
\hline & Amongst the employees establish share values. \\
\hline & To express their feeling about the change hold feedback meetings \\
\hline
\end{tabular}

Table 1: Shiraz industries problem statement using SWOT analysis. 
Citation: Mustafa M (2017) Leadership Innovation and Implement Organizational Change and Lead a New Initiative through Adoption of the Innovation and Change Management Practices for Shiraz Industries Private Limited Company: A Survey from Pakistan. J Bus Fin Aff 6: 278. doi: $10.4172 / 2167-0234.1000278$

Page 3 of 9

\begin{tabular}{|c|c|}
\hline Impact & Community \& Knowledge \\
\hline \multirow[t]{9}{*}{ Actions and Priorities } & Employees should be given freedom and team act should be more autonomous \\
\hline & Atmosphere within the company should sense of family and work efficiency and loyalty will be shared as a cause \\
\hline & Top management (CEO \& Directors) should be more supportive and facilitative \\
\hline & When doing change in implementation and planning involve the people who will be affected \\
\hline & $\begin{array}{c}\text { The objective, time frame and responsibilities should be clearly define and properly communicated and then give freedom to } \\
\text { experiment in the field. }\end{array}$ \\
\hline & In the organization create sense of cohesion \\
\hline & In change situation ask for lot of advice \\
\hline & Amongst the employees establish share values. \\
\hline & To express their feeling about the change hold feedback meetings \\
\hline
\end{tabular}

Table 2: Strategic priority using the Collaborate Quadrant.

\begin{tabular}{|c|c|}
\hline Impact & Innovation \& Growth \\
\hline \multirow[t]{7}{*}{ Actions and Priorities } & $\begin{array}{c}\text { Top management should be more visionary, individual risk taking, more innovative, creating new challenges, entrepreneurial and give } \\
\text { new services and products. }\end{array}$ \\
\hline & For producing innovative ideas and establishing goals hold people accountable \\
\hline & For diversity employees and hire new staff \\
\hline & Open and flexible workplace should be created \\
\hline & Create such a climax when people fail they feel free to admit \\
\hline & Future of the company should be forecasted \\
\hline & Action learning should be encouraged \\
\hline
\end{tabular}

Table 3: Strategic priority using the Create Quadrant.

\begin{tabular}{|l|r|}
\hline Impact & Innovation \& Growth \\
\hline Actions and Priorities & \begin{tabular}{r} 
Approach of top management should not act as hard driving competitors who always seek to the deliver the goods \\
First time give customers what they want to and to maintain those expectations work hard by giving level of service, which they never \\
requested of, expected by giving them surprises \\
In fast moving workplace make real time decisions \\
\cline { 2 - 2 }
\end{tabular} \\
\cline { 2 - 2 } & $\begin{array}{c}\text { As a key feature of the vision make continuous improvement } \\
\text { Make easy for customers and employees to complain and give suggestions } \\
\text { Through project portfolio management maximize the value }\end{array}$ \\
\hline
\end{tabular}

Table 4: Strategic priority using the Compete Quadrant.

\begin{tabular}{|l|r|}
\hline \multicolumn{1}{|c|}{ Impact } & Efficiency and Quality \\
\hline Actions and Priorities & Top management to quit the bureaucratic command style and respect the people and give power to the staff. \\
\cline { 2 - 3 } & Proper marketing department should be made in the company for smooth functioning \\
\cline { 2 - 2 } & To measure success establish past performance as the standard \\
\cline { 2 - 3 } & Internal process work should be made routine \\
\hline Look for the measure of improvement not just goal and task accomplishment \\
\hline Role and responsibilities of marketing department should be clearly established
\end{tabular}

Table 5: Strategic priority using the Control Quadrant.

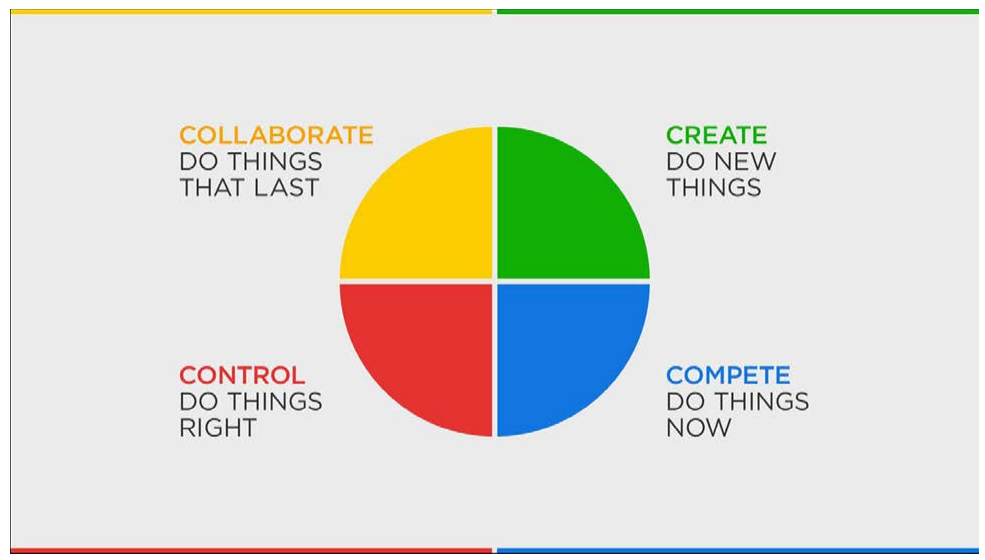

Figure 2: Innovation Genome Model for Shiraz Industries private limited. 
Citation: Mustafa M (2017) Leadership Innovation and Implement Organizational Change and Lead a New Initiative through Adoption of the Innovation and Change Management Practices for Shiraz Industries Private Limited Company: A Survey from Pakistan. J Bus Fin Aff 6: 278. doi: $10.4172 / 2167-0234.1000278$

Page 4 of 9

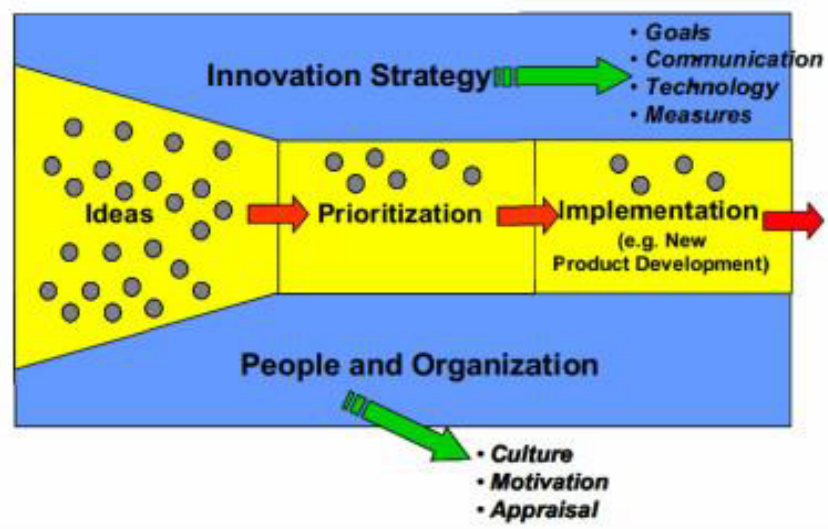

Figure 3: Design thinking methodology.

Prioritization: 1 . Top management to choose best ideas to ensure efficient process for development into innovation process, new products and services. 2. To analyze return on individual projects and risk use of suitable tools will be required. 3. Carefully assign the innovation projects with limited resources for the implementation. 4. Customers need and demands in the market to be given priority. 5 . To check the portfolio of innovation project match and balanced with the company innovation strategy from across the range of projects, managers need to collate the information. 6 . For future management team should collect the information on portfolio decision to learn from previous decision and review it.

Implementation: 1 . To compete in the market the focuses should be on efficiently and quickly development of combination of process or new product, services. 2. Through effective prototyping, testing and cross-functional team development time can be achieved faster. 3. For the new product successful marketing launch is essential.

People and organization: 1 . To increase the innovation output effective organizational structure should be created that includes the job design, training and hiring policies. 2. Employees should be motivated for constant innovative activities by creating a unique, open and friendly company culture. 3. Top management should focus and maintained effective reward and recognition programs.

\section{Kotter's Change Model for Shiraz Industries Private Limited}

The three dimensional linkage between organization, individual employees and teams for the organizational development will be used (Figure 4).

\section{Establish a sense of urgency}

- Top management should take the pulse of their company and understand the sense of urgency.

- For effectiveness and efficiency of the organization and to adopt the change the state of the organization should be determined.

- To compete with the competitors the company major need is to make a proper marketing department for the company.

- Marketing and advertising funds should be allocated to the sales/marketing teams for efficient publicity.

- The benefits of the change to be explain and realize to the employees.
- Motivate and convince the main supporting group.

- Give proposal of change, which is more value creating and inspiring.

- Show employees what can happen in future and identify the potential threats.

- Opportunities should be properly examine and exploit.

\section{Pull together the guiding team}

- Top management need to identify the key stakeholder and the true leaders in the organization.

- Within the change coalition works on building the team.

- In the organization weak area of the team should be check and ensure that good mix of people should be there in all levels in the company.

- Power and strength should be reflected from the team so that progress cannot be block from left outs.

- Commitment and strong trust can be made of all the viewpoints given by the relevant department to take intelligent decision.

- The leading capacity of the change should be built to recognize the opportunities.

\section{Create a vision}

- Top management to convey employees the clear picture of future and how it will look like.

- Management should often practice the vision speech.

- The goals for the vision should be attainable and realistic.

- With the space of expansion vision should be flexible as per requirement.

- Focused on the decision-making process guidelines.

\section{Communicate the vision}

- Simple and formal language should be used for communication, which should be usable and understandable.

- The power of two-way communication is more than one-way communication.

- Honestly and openly people concerns and anxieties to be address. 


\section{"Kotters Eight Steps of Change"}

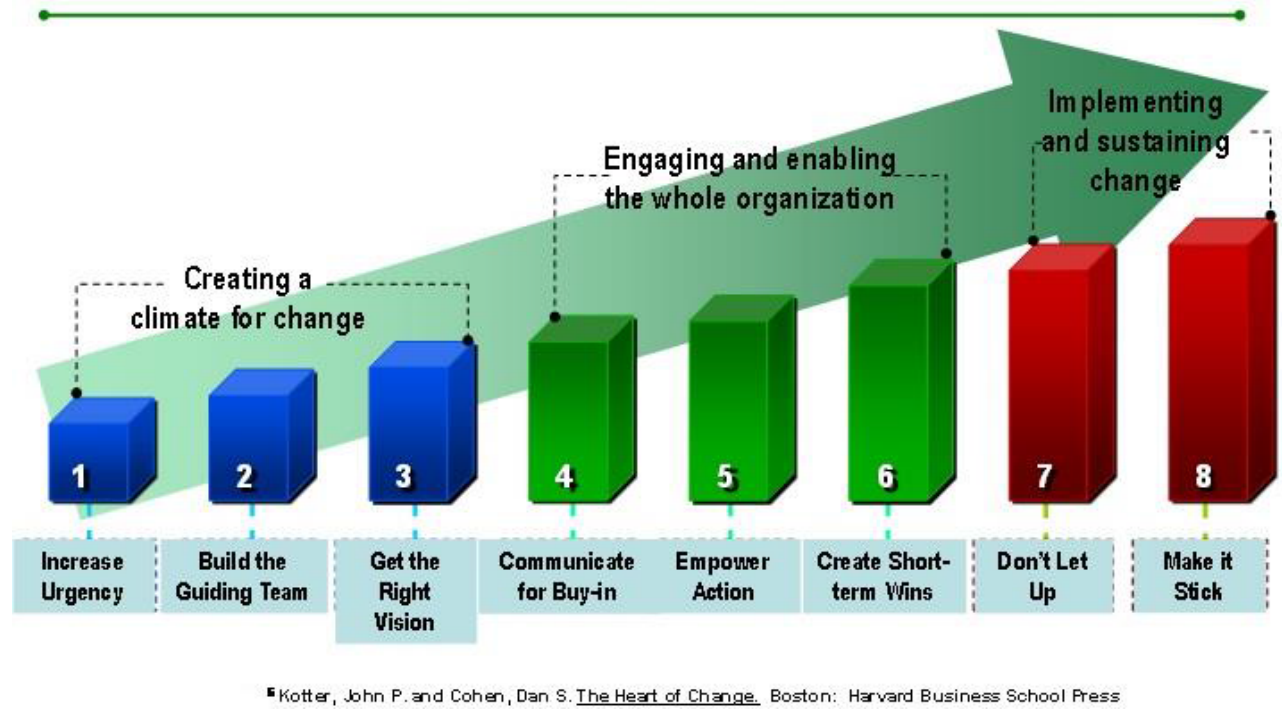

Figure 4: Kotter's 8 step change model.

\section{Empower others to act}

- The key persons or change leaders are to be identifying to deliver the change.

- Identify and help people who are resisting for the change and look for their needs.

- People involve in making the change should be recognize and rewarded.

- To see vision is in line within the organization look at the organizational structure, performance and job description.

\section{Plan and create short-term wins}

- Justifications on investment for each project will not be possible and early target should not be chosen which are expensive.

- Pros and cons potential of company targets should be thoroughly analyze. The entire change initiative can be hurt if early goals can't be succeeded.

\section{Don't let up}

- Victory should not be declared too early because many change projects fails.

- After every win what need improvement and what went right should be analyze.

- Learn about continuous improvement of the ideas.

- For continue building of achievement momentum organization should set the goals.

\section{Make change stick}

- Whenever top management get change tells success stories and talk about progress.

- When enrolling, training new staff changes values and ideals should be included.
- The key members of the original change coalition should be publicly recognized and all the new or old staff should remember their contributions.

\section{McKinsey 7S Model for Shiraz Industries Private limited}

\section{Strategy}

- Top management has to concentrate of the marketing strategy to penetrate into competitive market (Figure 5).

- To achieve the objectives excellent level of customers and client's services should be offered.

- To increase the revenue and company share in the market effective marketing teams and staff should be in place.

- Marketing teams to do proper field survey and put emphasis on advertising with the customers' demands and need.

- To sustained competitive advantage and achieve success develop long term strategy by strong vision, values and mission.

\section{Structure}

- Shiraz Industries should make a proper hierarchy of the company and establish proper formal marketing department.

- Marketing team structure needs to be properly enrolled through skilled and expert sales/marketing members.

- All the marketing staff should give progress to the marketing manager specifically for doing the field surveys and to get the customer need and get the feedback of the market, to generate the profit, and so that organizational efficiency can be increased.

- All the departments to have the centralized plan of action so that all the activities are aligned and coordinated.

\section{System}

- Proper check and balance for different areas of the market should be done through shift rotation system on daily basis. 
Citation: Mustafa M (2017) Leadership Innovation and Implement Organizational Change and Lead a New Initiative through Adoption of the Innovation and Change Management Practices for Shiraz Industries Private Limited Company: A Survey from Pakistan. J Bus Fin Aff 6: 278. doi: $10.4172 / 2167-0234.1000278$

Page 6 of 9

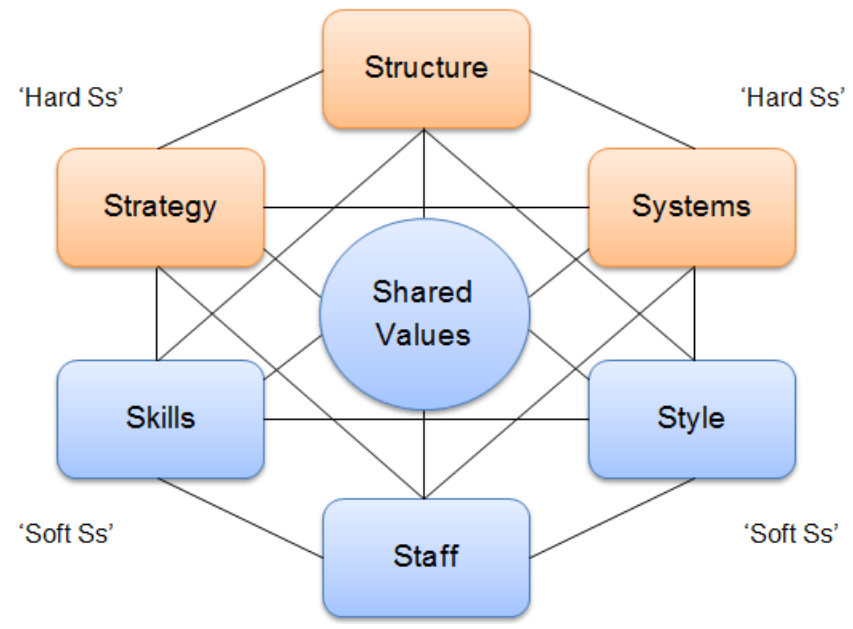

Figure 5: McKinsey $7 \mathrm{~S}$ model.

- Exact job description for the work place should be used to reduce the potential conflicts and this way work process will be more efficient and interesting.

- Marketing teams should be properly monitored and get the evaluation of the marketing survey.

- Proper record to be maintained and have the accountability that runs the system.

\section{Shared values}

- Giving good service and meeting the needs of the existing market by lowering the cost of the product, accessing new ones through innovation.

- Company should improve the quality, reliability of inputs and distribution.

- Improve the external framework and develop local cluster that supports the company operations.

- Growth in new market sale through new application of existing product.

\section{Style}

- Proper teamwork should be given with full liberty and more autonomous.

- Top management should frequently interact with the staff to give symbolic value.

- Top management attitude towards staff should be more facilitative and supportive.

\section{Staff}

- Skilled and expert marketing staff to be employed in the marketing department.

- Competent marketing manager to be appointed for the overall supervision of the department.

- Motivate the staff through appreciation and rewards.

- Trained and educate the staff with norms and professionalism to look more efficient than the competitors to attract the customers.
- Loyal and trust worthy people to enrolled in the company.

Skills

- Skilled and train staff to be employed which can reinforce the new strategy and structure during organizational change.

- Skills and expertise of the staff should be monitored by daily or weekly progress and achievements.

\section{Evidence Review}

\section{Introduction}

In today's highly competitive world, successfully put in place innovation gives advantage to organizations; industries and can even improve the status of a nation. To refine what already exists is also as effective as creating something new which is innovative [2]. In order to meet or beat competition, business seekers give huge importance to product innovation and for this the management keep thinking broadly and strategically and operate from broad perspective [3]. The other important areas where innovation gives a competitive edge to the competitors include process, production methods, suppliers and the markets.

\section{Transformational leadership}

Increased interest is observed in transformational leadership in the field of human services field there is increase in interest [4-6] Transformational leadership is concerned with the individual potential and motivation with the value based framework for his or her own interest and for the organization [7].

Types of Models for Innovation: For the innovation management two models will be used for this study:

- Innovation Genome

- The Pentathlon Framework

Innovation genome: The four quadrants of the model as shown in Figure 1 is the representation of the Innovation Genome. The different forms of value like practices and characteristics represent each quadrant of Innovation Genome. For the organizations, markets and individuals essentially the genome quadrants functions in a same way. The ability of an organization in specific situation to produce specific innovation can be determine by the strength, weakness and the four quadrants interactions with each other [2].

The quadrants of innovation genome are: Collaborate, Control, Compete and Create. The key measures of the quadrants are recognizable and associated with the four best types of practices, which include: leadership behaviors, organizational practices and the environment of the workplace [8]. The innovation playbook of the company is also part and associated with certain tools of these quadrants. The quadrants is more incline towards the dominant and more stronger side as many individual use both hands so it is very useful to thinks as being left handed or right handed for these quadrants [9].

All the characteristics of the quadrants are possessed by the organization in the similar manner but some organizations have some features appearing more dominant and stronger as compared to other organizations. Quadrants become oppositional in nature sometimes when the organizations practices and focus one type of innovation and the other type of innovation gets affected, weakened and/or destroyed. In other words, a firm focusing on growth may attempt to organize for 
Citation: Mustafa M (2017) Leadership Innovation and Implement Organizational Change and Lead a New Initiative through Adoption of the Innovation and Change Management Practices for Shiraz Industries Private Limited Company: A Survey from Pakistan. J Bus Fin Aff 6: 278. doi: $10.4172 / 2167-0234.1000278$

Page 7 of 9

and experiment high-risk breakthrough with the incremental processes of low-risk that lead to greater efficiency at expense of innovation [8].

The organizations, which are more effective, are the ones, which have some proficiency in all areas. The quadrants depict the strength of the organization highlighting the areas where the organization has greatest competencies. It is useful to create a well-rounded group to work with the people of other quadrants who have strength and skill to manage an eye on strength of the people [8]. How successful is the organizations at changing existing processes are determine by the forces external to the organization and other factors. One part of the equation is the leadership style. An innovation varies in terms of nature, scale, degree of novelty etc. However, in each case it can be seen that the same basic process is operating [10].

The pentathlon framework: For managing innovation, Pentathlon Framework [11,12] addresses several process and soft organizational issues (Figure 2). Goffin and Pfeiffer [11] declares that companies should well perform in five area (as shown in figure 2) in order to successfully achieved the innovation management and ensure that efforts emerging from these areas are integrated.

As per Figure 2 for the success of the innovation in an organization the Pentathlon Framework five elements are complimentary and one will be at the expense of another is given too much emphasis [2]. Managers should not expect while implementing the Pentathlon to find the linear process rather on an ongoing basis where revision and iterations are needed for different elements. The firm with high performance in innovation as suggested in several studies for developing new services and innovative product usually use formal process [13-15].

In terms of degree of novelty, nature and scale innovation widely varies however; in each case same basic process is operating can be seen [10]. The management team with in their own organization must decide and keep in mind how to best implement, as they should know Pentathlon is a framework [2]. The primary consideration must be given to satisfaction of stakeholders particularly the customers when creating an innovation strategy. Whether wholesale change or incremental improvement the manager should take in consideration how to tackle these [2]. Managing creativity, generating ideas and knowledge is the second element of Pentathlon. In an organization, closely linked to the knowledge is the innovation, which requires creativity, and, to protect the resulting ideas it requires efficient and effective way of recognizing the requirement of the customers [2].

The third stage of Pentathlon is very vital that decides which ideas to be abandoned and which should be taken into precedence as for the organization ideas generated will not add all equal value. At various stages of development these decisions may be taken [2]. The organization should have a clear objective process to facilitate these difficult decisions against which the decisions are made. The implementation begins at fourth stage of Pentathlon after the idea has been selected. To ensure the customer's needs are being met throughout the implementation the customer must be central as with other stages [2].

To manage the higher level of risk the standard project management techniques is required for effectively implementing new ideas and the uncertainty surround innovation with some important additions. The four elements of the Pentathlon are underpins by the people and the organization, which is the fifth element as within a business this fosters an innovation culture. To identify what needs to be change and plan how closely the current culture is a useful first step in creating an innovation culture. For this analysis one useful tool is the cultural web [9].

\section{Change models}

When the organizational design is at question, the change model is a valuable tool that can be applied to many situations. These framework most common uses are:

- The organizational change to be facilitated

- Help new strategy to be implemented.

- To identify in future how each area may be changed.

- The merger of organizations to be facilitated

\section{McKinsey $7 \mathrm{~S}$ model}

In early 1980s Tom Peters and Robert Waterman developed the McKinsey 7s model and the model is used in to analyze the firm by two consultants working in McKinsey \& Company [16]. The main sources about the model can be used for academic work and for more studies on McKinsey 7s model [17-19].

Soft and hard area divided into seven areas of the organization in McKinsey model. The hard elements of the model are system, structure and strategy. When compare to soft elements they are easier to manage and identify. On the other hand, the foundation of the organization is the soft area and is hard to manage to create the sustained competitive advantage [20].

Strategy is a firm developed plan to successfully compete in the market and to achieve the sustained competitive advantage [20]. Structure represent that who is accountable to whom information and the way business units and division are organized. According to Daft [21], the organizational internal characteristics can be described by providing structural dimensions labels. In other words the firm organizational chart is the structure. It is one of the elements of the framework, which is easy to change, and is more visible [16].

The strategy and structure is supported by the informal and formal systems procedures. It is a process how decisions are made and the company procedures, which reveal daily activity of the business. Systems determine the area of the firm; during the organizational change it should be the main focus of the managers how the business is to be done [20].

The ability, which employees perform well in the firm, is their skills [20]. The competences and capabilities are also included. To assure the success of any project it is essential to have expert and skilled people as showed by several studies [22-25]. The main concern of this element is how they will reward, motivate recruit and educate the employees and what quantity and type of employees and organization will need [20]. The young and more educated workers are less resistant than old and less educated workers as suggested by Herold et al. [26]

Organizational culture and management chic is mainly refers by style [18]. It represents the way top level managers of the company manages the style and what symbolic value and action they use to interact with their employees [20]. The core of McKinsey 7s model is the shared values. In every organization they are the foundation the company actions and employee behavior is guided through these norms and standards [20]. Strong skills of leadership should be possessing [27], as well as managerial competencies, personal and business [28].

\section{Kotter's 8 step change model}

The Kotter's change management models has eight critical steps for an organization that is based on research how teams ensures the 
Citation: Mustafa M (2017) Leadership Innovation and Implement Organizational Change and Lead a New Initiative through Adoption of the Innovation and Change Management Practices for Shiraz Industries Private Limited Company: A Survey from Pakistan. J Bus Fin Aff 6: 278. doi: $10.4172 / 2167-0234.1000278$

Page 8 of 9

change has happened and how to go through that change and stick as follows [29].

Eight stages of this dynamic model can be organized into three different phases. "Creating the climate change" is the first phase that includes establishing a sense of urgency, developing strategy and vision and creating a guiding coalition [30]. "Engaging and enabling the organization" that includes creating short-term wins, empowering actions and the communication of the vision. "Implementing and sustaining the change" is the final stage of this model that includes in the culture anchoring new approaches, consolidating gains and more change to be producing [30].

\section{Creating a climate for change}

Establishing a sense of urgency is the first stage. In attempting change the biggest mistake is to allow complacency [29]. This is the critical step of this model the people will resist change and cling to the status quo if the sense of urgency will not establish amongst them. Why a change needs to occur by creating urgency will help and make people feel and see firsthand [31]. Creating a guiding coalition is the second stage of this model. To mobilize change the skills, which are required and needed by the members of the guiding team, is to have influence, knowledge and credibility [29]. Third stage is to develop a strategy and vision for the people to think and work.

\section{Engaging and enabling the organization}

Communicating the vision is the first stage of this phase. Once the vision has been established it is imperative that to all the groups it is frequently communicate and convincing and all the stakeholder of the group and the members should agree upon Neumeier [30]. Creating short-win and enabling action in this phase are the next two stages. At this stage to participate in making the changes and to remove the obstacles empower all the members and make them work together. What needs improvement and what went right it is important to analyze after every win [30].

\section{Sustaining the change and implementation}

In the organizational culture for anchoring new approaches and to produce more change and to consolidate gains are part of seventh and eight stages. Premature victory should not be declared is the warning of this stage [30]. In this phase the strategic steps and desired vision needs to be focused continuously until in the culture of the organization is becomes the permanent part and clearly reflects in the value and shared norms [32].

\section{Research Methodology}

To examine the skill leadership, innovation and change practices that management in a company need through emerging method to achieve the effective design of this study. The current information gathered from the management that could aid in an effort to identify what innovation and change management the leadership practices to effectively produce future marketing and sales leaders are critical.

\section{Research design}

To sought and understand the critical elements for innovation and change. The qualitative research method will be used for this study. A survey has been conducted to examine the managerial innovative practices and performance by taking the personal interviews of director, sales and marketing department team and general manager and group discussion amongst the employees.

\section{Research approach}

To gain the insight and attitude of the participant qualitative and ethnographic design approach has been used. Furthermore, to see the leadership innovation and change qualities of the leaders how they feel $[33,34]$.

\section{Research questions}

- For leadership why is vision important in an organization?

- What is the innovative approach importance in an organization?

- For an organization why is change needed?

\section{Target population}

The population, which is targeted for this research, was top management and subsidiaries of the polypropylene company (Figure 2).

\section{Data collection}

For the sample population for the research project telephonic interviews will be conducted.

\section{Data analysis}

To assess the reliability of the items measurement questionnaire will be used.

\section{Conclusion}

This study was set to explore the leadership, innovation and change practices in Shiraz Industries private limited company. The reason and motivation to conduct the study to see how the company is using the innovation and change strategy to compete in the market with the strong competitors. With the help of using the change and the innovation model the company was access and the strategic priorities and the implementation of these models on the company has been highlighted. As the company is facing difficulties the local and niche market the company should use innovation and change models strategies to overcome the difficulties in the field of marketing. Moreover, giving the staff initiatives, power and rewards is also the key factor to be emphasis in the company's policies, to strengthen the internal relationship and the company environment friendlier. Skilled and expert staff is the backbones of any organization.

\section{Recommendations}

- Shiraz Industries should make a proper company hierarchy.

- Marketing department should be formally introduced in the company.

- Marketing experts and skilled staff should be enrolled in the company.

- Increase the strength of the marketing department keeping in view the market demand and area of operations.

- Sufficient amount of funds should be allocated for marketing and advertising campaigns.

- Shiraz Industries should go into international market keeping in view the state of the art machinery with finest quality of production.

- To get the competitive advantage with the competitors review the cost of the product to attract the customers. 
Citation: Mustafa M (2017) Leadership Innovation and Implement Organizational Change and Lead a New Initiative through Adoption of the Innovation and Change Management Practices for Shiraz Industries Private Limited Company: A Survey from Pakistan. J Bus Fin Aff 6: 278. doi: $10.4172 / 2167-0234.1000278$

- Weekly monitoring of the staff expertise and skills in the field and their achievement and progress.

- To give attraction to the customers and competitors the staff should focus on professionalism and ethics while dealing with clients.

- Develop local cluster that supports the company operations and improve the external framework

- Centralized plan of action by all the departments so that all the activities are aligned and well-coordinated.

- To penetrate into competitive market top management has to concentrate on the company's marketing strategy

- Top management should focus and learn about continuous improvement of the ideas.

- To deliver the change the top management /leaders should identify the key persons and make proper use of their expertise.

- Identify the potential threats and show employees what can happen in future.

- To recognize the opportunities the leading capacity of the change should be build.

- Top management with limited resources for the implementation should carefully assign the innovation projects.

- Management should hold people accountable for producing innovative ideas and establishing goals.

- Management should involve the people who will be affected when doing change in implementation and planning.

\section{References}

1. Shirazindustry.Com. (2014) Shiraz Industries (Pvt) Ltd.

2. Goffin K, Mitchell R (2005) Innovation management. Basingstoke: Palgrave Macmillan.

3. Shateri M, Safari R, Hozhabrnejad N, Baghiabadi H (2016) Investigating the role of knowledge management as a tool for enhancing innovation and creativity in organizations. International Journal of Research 4: 82-89.

4. Fisher E (2009) Motivation and Leadership in Social Work Management: A Review of Theories and Related Studies. Administration in Social Work 33: 347-367.

5. Gellis ZD (2001) Social work perceptions of transformational and transactional leadership in health care. Social Work Research 25: 17

6. Mary NL (2005) Transformational leadership in human service organizations. Administration in Social Work 29: 105-118.

7. Middleton J, Harvey S, Esaki N (2015) Transformational Leadership and Organizational Change: How Do Leaders Approach Trauma-Informed Organizational Change...Twice? Families in Society: The Journal of Contemporary Social Services 96: 155-163.

8. Okoń-Horodyńska E, Zachorowska-Mazurkiewicz A, Sierotowicz T, Wisła R (2016) Gender, Innovation Capacity, and the Process of Innovation: A Case of Poland. Economics \& Sociology 19: 252-263.

9. Goffin K, Mitchell R (2010) Innovation management. Basingstoke: Palgrave Macmillan.

10. Tidd J, Bessant J, Pavitt K (2005) Managing Innovation. (3rd edn.), John Wiley \& Sons Ltd, UK.

11. Goffin K, Pfeiffer R (1999) Innovation Management in UK and German Manufacturing Companies. London, Anglo-German Foundation.

12. Oke A, Goffin K (2001) Innovation Management in the Service Sector Management Focus, Cranfield School of Management, UK, Summer Issue.
13. Griffin A (1997) PMDA research on new product development practices: Updating trends and benchmarking best practices. Journal of Product Innovation Management 14: 429-458.

14. Tatikonda MV, Rosenthal SR (2000) Successful execution of product development projects: balancing firmness and flexibility in the innovation process. Journal of Operation Management 18: 401-425.

15. Shaw NE, Burgess TF, Hwarng HB, Mattos C (2001) Revitalizing new process development in the UK fine Chemicals industry. International Journal of Operation and production Management 21: 1133-1151.

16. Hanafizadeh P, Ravasan A (2011) A McKinsey 7S Model-Based Framework for ERP Readiness Assessment. International Journal of Enterprise Information Systems 7: 23-63.

17. Pascale R, Athos A (1981) The art of Japanese management. Business Horizons 24: 83-85.

18. Peters T, Waterman RH (1982) In search of excellence. New York, NY: Harper and Rowe.

19. Waterman R, Peters T, Phillips J, (1980) Structure is not organization. Business Horizons 23: 14-26.

20. Ravanfar M (2015) Analyzing Organizational Structure Based on 7s Mode of Mckinsey. Global Journal of Management and Business Research: An Administration and Management 15: 8-9.

21. Daft RL (1998) Organization theory and design. Mason, OH: South-Western College Publishing.

22. Davenport T (2000) Mission critical: Realizing the promise of enterprise systems. Boston, MA: Harvard Business Press.

23. Skok W, Legge M (2002) Evaluating enterprise resource planning (ERP) systems using an interpretive approach. Knowl. Process Mgmt 9: 72-82.

24. Sumner M (1999) Critical success factors in enterprise wide information management systems projects. Paper presented at the Americas Conference on Information Systems

25. Wateridge J (1997) Training for IS/IT project managers: A way forward. International Journal of Project Management 15: 283-288.

26. Herold D, Farmer S, Mobley M (1995) Pre-implementation attitudes toward the introduction of robots in a unionized environment. Journal of Engineering and Technology Management 12: 155-173.

27. Mandal P, Gunasekaran A (2003) Issues in implementing ERP: A case study. European Journal of Operational Research 146: 274-283.

28. Kræmmergaard P, Rose J (2002) Managerial competences for ERP journeys Information Systems Frontiers 4: 199-211.

29. Kotter JP (1996) Leading Change. Boston, MA: Harvard Business Schoo Press.

30. Neumeier M (2013) Using Kotter's Change Management Theory and Innovation Diffusion Theory in Implementing an Electronic Medical Record. Canadian Journal of Nursing Informatics.

31. Campbell RJ (2008) Change management in health care. Health Care Manage 27: 23-39.

32. Chapman C, Ward S (1997) Project Risk Management- Process, Techniques and Insights. ( $2^{\text {nd }}$ edn), WILEY, UK.

33. Clark C (2010) From incivility to civility: Transforming the culture. Reflections on Nursing Leadership.

34. Creswell J (2014) Research design. Thousand Oaks, California: SAGE Publications. 